\title{
Biotechnologies de la reproduction : le clonage des animaux d'élevage
}

\author{
X.VIGNON, Y. HEYMAN, P. CHAVATTE-PALMER, J.-P. RENARD \\ INRA, UMR1198 Biologie du développement et Reproduction, F-78352 Jouy-en-Josas, France \\ Courriel :Xavier.Vignon@jouy.inra.fr
}

Les recherches de l'INRA sur le clonage des animaux se sont distinguées par plusieurs réussites mondialement reconnues. Les premières applications dans les domaines thérapeutiques et agronomiques ont vu le jour mais sont encore limitées par le faible taux de survie des fotus et nouveau-nés clonés. Des pistes originales de recherche sont explorées pour comprendre les effets à long terme de cette nouvelle méthode de reproduction.

Les recherches sur le clonage par transfert de noyau participent à l'émergence d'une nouvelle méthode de reproduction des animaux de rente. Celle-ci élargit la panoplie des biotechnologies de la reproduction mises en œuvre depuis le milieu du siècle dernier dans les élevages, d'abord avec l'insémination artificielle chez l'espèce bovine, puis avec la maîtrise des cycles ovariens, la transplantation embryonnaire et la production d'embryons in vitro.

Le clonage animal permet de reconstituer des embryons à partir de cellules différenciées issues d'un animal adulte. Les embryons ainsi reconstitués peuvent ensuite être transplantés dans des femelles receveuses pour assurer le développement à terme et obtenir la naissance d'un ou plusieurs individus qui portent le même génome nucléaire que le donneur de cellules. La méthode utilisée chez la plupart des espèces est la fusion de la cellule donneuse de noyau avec un ovocyte maturé et préalablement énucléé par micromanipulation. La cellule peut provenir de différents tissus d'un animal adulte (fibroblaste de la peau, cellule du cumulus ovarien...). Les ovocytes utilisés lors des séries de reconstitutions d'embryons proviennent de ponctions ovariennes de femelles dites «donneuses d'ovocytes», ce qui implique que les clones obtenus auront généralement un génome mitochondrial différent, et que seuls leurs gènes nucléaires seront identiques.

L'efficacité globale du clonage est très variable mais reste en général faible, moins de 5\% des embryons transférés aboutissant à un jeune viable dans toutes les espèces. L'impact de cette technologie sur l'élevage est donc encore très modeste en comparaison des autres biotechnologies de la reproduction (Colleau et al 1998, Bousquet et Blondin 2004). Cependant, parallèlement aux progrès techniques constants dans les différentes étapes du clonage, les recherches sur le transfert de noyaux ont permis d'apporter de nouveaux outils d'exploration pour comprendre les mécanismes qui concourent à la mise en place des premières différenciations cellulaires d'un organisme vivant. A l'INRA, nous avons pu tirer parti de plusieurs modèles animaux pour progresser dans ce domaine de recherche fondamentale. En particulier, les espèces domestiques présentent des caractéristiques de reproduction et de développement avantageuses pour l'étude des interactions complexes qui sont abordées dans l'ère de la «post-génomique».

L'application de ces recherches à la production d'animaux par clonage a conduit notre équipe à s'impliquer dans une démarche collective d'évaluation de la qualité et de la sécurité des produits issus du clonage (Heyman et al 2007b), et à contribuer aux débats suscités par la naissance des premiers clones somatiques et qui dépassent largement la seule communauté scientifique. Ces apports seront présentés, et souvent illustrés par des exemples concrets chez le bovin, espèce chez laquelle la technique est largement la plus efficace, et qui constitue également un modèle particulièrement approprié pour l'étude des physiopathologies de la gestation.

\section{1 / Du clonage embryonnai- re au clonage somatique, bientôt 20 ans de recher- ches à I'INRA}

Les années 80 ont été marquées par la recherche de l'optimisation de la technique de transfert d'embryons chez les ruminants en démultipliant le nombre d'embryons transplantables à partir d'une même donneuse superovulée. Les techniques de micromanipulation avec tout d'abord la scission d'embryons (Ozil et al 1982), puis le clonage à partir de cellules embryonnaires (Heyman et al 1990) ont été développées pour répondre à cet objectif.

A l'INRA, ces travaux ont contribué au développement de recherches actives sur la totipotence cellulaire et la reprogrammation de noyaux cellulaires. Ils conduisirent à l'obtention de premiers clones embryonnaires chez le lapin et le mouton (Heyman et al 1990). Suite à ces premiers résultats, un programme financé dans le cadre d'un appel d'offres du Ministère de l'Enseignement Supérieur et de la Recherche sur les sauts technologiques a permis de développer ces recherches chez les bovins et d'obtenir dès 1993 la naissance d'un clone de 5 veaux mâles à partir d'un seul embryon. Ces travaux visaient à utiliser des cellules donneuses de noyaux engagées de plus en plus loin dans le développement embryonnaire (jusqu'au stade morula), ainsi qu'à optimiser la préparation de cytoplasmes ovocytaires receveurs compatibles avec ce type de cellule donneuse (Chesné et al 1993). 
Cette première période de l'histoire du clonage des mammifères à l'INRA a permis d'élaborer les bases des protocoles utilisés à des fins de recherche finalisée comme par exemple pour un programme associant le sexage de l'embryon donneur de cellules (LeBourhis et al 1998).

Compte tenu du petit nombre de cellules disponibles quand un jeune embryon est utilisé comme source de noyaux (une morula compte environ une trentaine de cellules seulement) nos travaux se sont rapidement orientés vers des sources alternatives de cellules donneuses, notamment des cellules somatiques différenciées d'origine fœtale. Ces premières expériences nous ont permis de démontrer dès 1998, soit un an seulement après la naissance de la brebis Dolly, qu'il était possible d'obtenir un bovin cloné (la vache Marguerite) à partir de cellules issues de tissus musculaires (Vignon et al 1998). La même année, plusieurs veaux clonés issus de noyaux de cellules de peau d'animaux donneurs adultes sont nés sur la station expérimentale de Bressonvilliers (Renard et al 1999, Heyman et al 2002, ChavattePalmer et al 2004). Ces travaux ont alors pris une place centrale dans les recherches fondamentales sur la reprogrammation du noyau embryonnaire au cours du développement précoce (Renard 1998). Ils ont aussi permis de révéler l'existence d'effets à long terme de la reprogrammation sur le développement fotal. Ceci a contribué à souligner l'importance de perturbations fœto-placentaires très précoces dans l'apparition de physiopathologies de l'animal adulte, ceci grâce à la mise en place d'études systématiques sur le suivi des gestations et l'état de santé des clones depuis la période périnatale (Chavatte-Palmer et al 2004).

Les différentes phases du processus de transfert nucléaire ont été précédemment décrites (Heyman et al 2005, figure 1). Elles sont jalonnées d'étapes nécessitant un approfondissement des connaissances, encore très réduites, sur les mécanismes fondamentaux qui contribuent à la reprogrammation de l'activité des gènes du noyau donneur (Renard et al 2002). Chacune de ces étapes est étroitement dépendante de l'amélioration de procédures techniques qui continuent à être affinées pour tenter d'augmenter l'efficacité du clonage. Au cours de la période de clivage du développement embryonnaire normal, l'organisation du noyau, notamment celle des protéines étroite- ment associées à l'ADN nucléaire et qui forment la chromatine, subit un processus de maturation. Ce processus accompagne la transition qui conduit à la transcription exclusivement zygotique. Les facteurs impliqués dans la régulation de l'expression des gènes comme l'architecture nucléaire, la structure de la chromatine ou la méthylation de l'ADN, font maintenant partie des paramètres analysés dans le but de mieux connaître les perturbations épigénétiques susceptibles de modifier durablement le développement préet post-implantatoire de l'embryon
(Vignon et al 2002, Beaujean et al 2005). De plus, une approche génomique est depuis quelques années utilisée pour mieux caractériser l'impact de ces perturbations sur la régulation de l'expression des gènes à des stades clés du développement. Des analyses utilisant la technologie des micro-arrays d'ADNc ont ainsi été réalisées dans des programmes collaboratifs sur les bovins. Elles démontrent une reprogrammation significative dans les embryons clonés au stade blastocyste (Smith et al 2005), mais également l'apparition de dérégulations placentai-

\section{Figure 1. Principe du clonage par transfert de noyau somatique.}

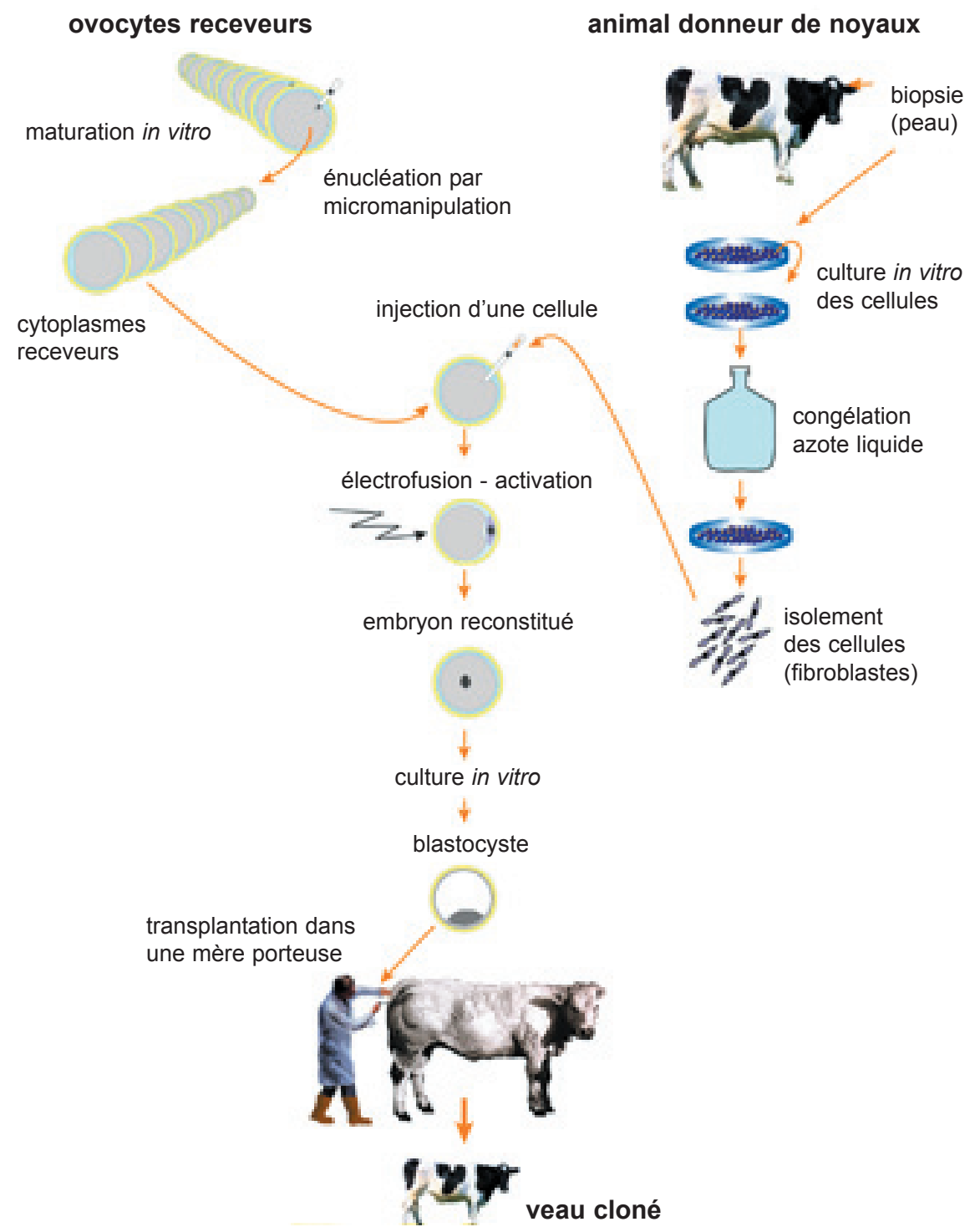

Les ovocytes receveurs sont énucléés après leur maturation jusqu'au stade métaphase II. Les cellules de l'animal donneur sont généralement issues d'un prélèvement de tissu mis en culture pour en dériver des cellules qui peuvent être multipliées et conservées dans l'azote liquide avant leur utilisation pour le clonage. Au moment du clonage, chaque cellule donneuse est insérée sous la zone pellucide d'un ovocyte énucléé, et accolée au cytoplaste. Une décharge électrique permet de fusionner la cellule entière avec le cytoplaste, un embryon est ainsi reconstitué avec le noyau somatique, puis activé pour commencer son développement in vitro. Après une période de culture in vitro, l'embryon est transplanté, généralement au stade blastocyste, dans une mère porteuse synchronisée pour recevoir des embryons de ce stade. Les clones sont souvent délivrés au terme par césarienne. 
res à des stades plus tardifs (Everts et al 2008). Ceci suggère que les perturbations induites par le clonage ont des conséquences essentiellement lors de la différenciation tissulaire chez l'embryon cloné, comme cela a été observé chez la souris (Jouneau et al 2006). Elles nous ont permis, en utilisant l'embryon bovin comme modèle, de mettre en évidence des mécanismes originaux de différenciation des premiers lignages cellulaires (Degrelle et al 2005).

\section{2 / Situation du clonage somatique et contribution de I'INRA}

L'application des expériences de transfert de noyau à la reproduction de mammifères pour la conservation de génotypes d'exception a majoritairement été développée au Royaume-Uni dans ses étapes initiales, que ce soit en utilisant des cellules embryonnaires (Willadsen 1986) ou des cellules somatiques (Wilmut et al 1997). La naissance du mouton Dolly, issu du transfert d'un noyau de cellule épithéliale de glande mammaire dans un ovocyte énucléé a pour la première fois montré que le noyau de cellules différenciées pouvait être replacé dans un état fonctionnel semblable à celui d'un œuf fécondé. Ce précédent a été rapidement suivi par l'obtention de naissances de clones bovins aux Etats-Unis (Cibelli et al 1998), en France (Vignon et al 1998) et au Japon (Kato et al 1998). La première souris clonée par transfert de noyau de cellule somatique a été obtenue la même année avec des cellules de cumulus (cellules différenciées situées autour de l'ovocyte) (Wakayama et al 1998). Ce modèle expérimental a ensuite été utilisé dans plusieurs labo- ratoires pour l'étude des processus fondamentaux de reprogrammation (Meissner et Jaenisch 2006), et l'obtention de cellules souches embryonnaires (cellules ES) à partir d'embryons clonés (Wakayama 2007). Il est également utilisé à l'INRA pour l'analyse des effets de la reprogrammation du noyau transplanté sur le développement ultérieur des embryons (Zhou et al 2001, Jouneau et al 2006).

Après des ajustements techniques propres à chaque espèce, les annonces de reproduction par clonage somatique se sont succédé, notamment sous l'impulsion d'entreprises privées américaines. Actuellement le clonage somatique a été réalisé chez 13 espèces de mammifères (bovins, ovins, caprins, porcins, souris, rats, lapins, mules, chevaux, furets, chats, chiens, cervidés) mais avec des taux de succès encore très variables en raison notamment de pertes fœtales importantes (cf. tableau 1 incluant les 12 espèces pour lesquelles le plus de données ont été obtenues). Les premières chèvres clonées ont été produites à partir de cellules dérivées d'un fotus transgénique, confirmant l'intérêt de l'association entre le clonage et la transgenèse pour obtenir, à partir de cellules donneuses de noyaux modifiées génétiquement en culture, des animaux produisant par exemple une protéine recombinante dans leur lait (Baguisi et al 1999). Peu après, des équipes américaine et japonaise ont obtenu les premières naissances de porcs clonés, respectivement à partir de cellules de granulosa et de fibroblastes fœtaux (Polejaeva et al 2000, Onishi et al 2000). Depuis le début des années 2000, le nombre d'espèces clonées dans le monde s'est accru, malgré des difficultés inattendues pour certaines comme le lapin ou le rat. On estime à environ 4000 le nombre de bovins clonés actuellement nés dans le monde et à 1500 le nombre de porcs. Dernier en date parmi les gros mammifères d'élevage, le cheval a été cloné en Italie (Galli et al 2003), et une douzaine de poulains sont nés depuis aux Etats-Unis.

\section{1 / Après la vache Marguerite, premières mondiales pour le lapin et le rat}

La vache Marguerite, le premier clone de cellules musculaires produit dans le monde, connut un grand moment de vie médiatique lors de sa présentation sur grand écran par l'INRA au salon de l'Agriculture 1998. Un an après la naissance de la brebis Dolly, la communauté scientifique continuait en effet à émettre des doutes sur la réalité même du clonage alors que le public s'était déjà emparé du clonage pour en rejeter l'idée de toute application à l'homme. La naissance de Marguerite permit de confirmer de façon irréfutable les résultats de l'équipe de Ian Wilmut et Keith Campbell (Buttler 1998). Ce succès a encouragé le laboratoire à poursuivre ses travaux en explorant les possibilités du clonage avec deux espèces de laboratoire, le lapin et le rat. Ces deux espèces, utilisées en recherche biomédicale ou pour la pharmacologie et la toxicologie, présentent plusieurs avantages par rapport à la souris en raison de leur taille et d'une plus grande proximité comme modèle pour certaines pathologies humaines.

Le premier clone de rat fut obtenu dans notre laboratoire (Zhou et al 2003) grâce à la mise au point d'un protocole spécifiquement adapté à l'ovocyte de cette espèce qui présente le défaut de

Tableau 1. Effectif de clones obtenus chez 12 principales espèces de mammifères dans le monde.

\begin{tabular}{|l|c|c|c|c|}
\hline \multicolumn{5}{|c|}{ Espèces clonées, nombre de descendants et efficacité globale du clonage somatique } \\
\hline Mouton & $\begin{array}{c}\text { Première naissance } \\
\text { rapportée }\end{array}$ & $\begin{array}{c}\text { \% descendant viable/ } \\
\text { embryons transferrés }\end{array}$ & $\begin{array}{c}\text { Nombre estimé de } \\
\text { clones nés vivants }\end{array}$ & $\begin{array}{c}\text { Nombre estimé } \\
\text { de descendant F1 }\end{array}$ \\
\hline Souris & 1997 & 8 & 500 & - \\
\hline Bovin & 1998 & 2 & $>300$ & - \\
\hline Chèvre & 1998 & $15-20$ & $>3500$ & $?$ \\
\hline Porc & 1999 & 3 & $>500$ & $200 ?$ \\
\hline Chat & 2000 & $3-5$ & 1000 & - \\
\hline Lapin & 2002 & $<1$ & 12 & 30 \\
\hline Mule & 2002 & 1 & 2 & - \\
\hline Cheval & 2003 & 1 & 22 & 15 \\
\hline Rat & 2003 & 1 & 4 & 2 \\
\hline Chien & 2003 & $<1$ & 2 & 12 \\
\hline Furet & 2005 & 1 & 3 & \\
\hline
\end{tabular}

Source EFSA (2008). 
s'activer spontanément lors de sa préparation avant le transfert d'un noyau étranger. Le recours à un inhibiteur du protéasome, le MG 132, combiné à la mise au point d'une technique permettant de réaliser en une seule phase de micromanipulation l'injection du noyau donneur et l'énucléation de l'ovocyte, a permis l'obtention d'un clone de plusieurs rats viables. Ceci démontre l'importance de mener de front l'analyse de mécanismes fondamentaux avec la mise au point de nouvelles techniques.

Chez le lapin, le clonage somatique s'est avéré particulièrement difficile à réaliser malgré un taux de développement satisfaisant des embryons reconstitués in vitro. En effet, très peu de gestations vont jusqu'au terme après transplantation des embryons clonés. Néanmoins grâce à notamment une bonne synchronisation des mères porteuses avec les embryons clonés, notre laboratoire a obtenu pour la première fois la naissance de lapereaux par clonage somatique à partir de cellules du cumulus ovarien (Chesné et al 2002). Ce résultat n'a pu être reproduit que très récemment dans d'autres laboratoires en Chine (Li et al 2006) et en Hongrie (Meng et al 2008)

\section{2 / Une importance particuliè- re pour l'espèce bovine}

Le bovin est l'espèce chez laquelle le clonage est le plus efficace. Une des explications tient certainement au fait que cette espèce a pu immédiatement bénéficier des autres biotechnologies de l'embryon (maturation ovocytaire in vitro, culture in vitro, transfert d'embryons) déjà largement éprouvées (Colleau et al 1998). C'est bien chez le bovin qu'une équipe Néo-Zélandaise a réalisé pour la première fois et avec succès un programme de préservation d'une race en voie d'extinction en ayant recours au clonage d'une vache âgée (Wells et al 1998). C'est aussi chez cette dernière espèce que les premiers rapports compilant l'observation d'anomalies de développement liées à la technologie du clonage ont été publiés (Hill et al 1999, Renard et al 1999). La variabilité entre les résultats publiés demeure toutefois encore peu comprise, une des causes majeures semblant être le génotype des animaux donneurs dont sont issus les clones. Nous avons rapporté l'exemple de séries d'embryons clonés obtenus à partir de cultures de cellules issues de deux vaches donneuses adultes de même race qui donnent des résultats très contrastés en terme de naissance malgré l'utilisation de protocoles identiques. Dans un cas 22 veaux sont nés à partir de 120 transplantations $(18,3 \%)$ contre 4 seulement $(3,3 \%)$ dans l'autre cas pour un nombre de receveuses équivalent (Renard et al 2007). Des résultats similaires ont été rapportés dans une étude portant sur des résultats de clonage bovin aux Etats-Unis et en Amérique du Sud où près du quart des lignées cellulaires utilisées comme source de cellules donneuses ont été inaptes à donner des naissances (Panarace et al 2007). Ils montrent que l'origine des cellules est un paramètre déterminant dans le clonage reproductif animal.

Au cours des dix dernières années, nous avons obtenu 88 veaux clonés de différents génotypes au sein de l'Unité expérimentale INRA-Bressonvilliers. Actuellement 39 d'entre eux sont toujours suivis dans le cadre de protocoles expérimentaux et constituent de fait le «cheptel» de clones bovins le plus important d'Europe. Les succès obtenus chez cette espèce ont attesté que le transfert de noyau était un outil pertinent pour tester et caractériser l'ensemble des conditions dans lesquelles un embryon peut poursuivre son développement de manière harmonieuse ou bien au contraire dévier vers un développement anormal. Chez la souris, très peu de laboratoires ont obtenu des descendants viables issus de clonage à partir de cellules somatiques, ce qui en fait un modèle moins pertinent à cet égard.

\section{3 / Des avancées sur les cellules somatiques et les interactions noyau-ovocyte}

Quand un noyau est introduit dans un ovocyte receveur énucléé, sa chromatine subit des remaniements de son organisation qui dépendent, parmi d'autres facteurs, du stade du cycle cellulaire auquel se trouve la cellule donneuse de noyau et l'ovocyte receveur énucléé. Le cytoplasme receveur peut être utilisé soit avant d'induire l'activation de l'ovocyte énucléé, donc au stade métaphase II (MII), soit après cette activation, donc dans un état interphasique. L'introduction d'un noyau dans le cytoplasme d'un ovocyte énucléé mais non activé soumet ce noyau à l'action des facteurs de l'ovocyte mature (MPF, $M$ Phase Promoting Factor notamment). C'est une stratégie qui suppose une étroite synchronisation entre la cellule donneuse de noyau et l'ovocyte receveur et a conduit un certain nombre de laboratoires à suggérer que les cellules donneuses de noyau devaient être induites en phase de quiescence (phase G0 du cycle cellulaire) avant d'être utilisées (Wilmut et al 1997).

Chez la souris, une durée minimale d'exposition de la chromatine condensée au cytoplasme de l'ovocyte non activé semble décisive pour le succès du clonage (Wakayama et al 1998). Ainsi, l'utilisation de noyaux en métaphase s'est révélée avantageuse pour la réorganisation d'un noyau somatique en noyau totipotent (Zhou et al 2001). Il n'en est pas de même chez le bovin où le transfert d'un noyau donneur dans un ovocyte déjà activé ou que l'on a laissé «vieillir» quelques heures in vitro (Chesné et al 1993) permet aussi d'obtenir un développement à terme (Vignon et al 1998). Cette approche, sur laquelle nous avons centré une partie de nos études, vise à éviter les risques d'aneuploïdies (nombre de chromosomes différent de $2 \mathrm{n}$, donc anormal) associés à la condensation du noyau induite par le MPF. En effet, la condensation prématurée de la chromatine peut conduire à une régulation anormale de la réplication de l'ADN, lorsque les noyaux donneurs utilisés sont en phase S de leur cycle cellulaire par exemple (Adenot et al 1997). Depuis, nous avons observé que l'exposition des cellules donneuses à un milieu dépourvu de sérum (induction de la phase G0) n'améliorait pas les taux de réussite après transfert dans un ovocyte receveur chez la vache, même si ce dernier est en métaphase II (Vignon et al 2002). Ces données montrent que les évènements qui conduisent à réorganiser la chromatine de noyaux somatiques en chromatine zygotique font appel à des mécanismes qui ne se réduisent pas au seul ajustement initial des cycles du noyau donneur et du cytoplasme receveur. Le rôle de facteurs ovocytaires spécifiques, la cinétique des premières divisions de l'œuf, la séquence de régulations qui aboutissent à l'établissement des premières différenciations au stade blastocyste sont aussi à prendre en compte (Renard 1998, Vignon et al 2002, Gall et al 2008). L'absence de réponse à ces questions fondamentales explique au moins pour partie la faible efficacité du clonage.

\section{4 / Des connaissances sur le développement fotal et post- natal après transfert d'em- bryons clonés}

Quel que soit le mode utilisé pour la reconstruction des embryons, les taux de développement à terme, sont faibles. 
Dans notre laboratoire, en moyenne 8 à $10 \%$ des blastocystes issus de noyaux de fibroblastes de bovin sont capables de se développer en veaux viables alors que c'est le cas pour environ $50 \%$ d'entre eux lorsqu'ils sont issus de fécondation in vitro (Heyman et al 2002). Ces blastocystes ont pourtant une apparence morphologique identique à celle de blastocystes non clonés bien que le rapport du nombre de cellules du bouton embryonnaire au nombre total de cellules soit plus faible. La majorité des arrêts de gestation survient rapidement pendant la période péri-implantatoire. $\mathrm{Au}$ cours du premier trimestre de la gestation chez la vache, les pertes fotales précoces sont associées à des perturbations de la vascularisation du placenta. Cependant, bien que les fœtus soient plus petits que la moyenne (ChavattePalmer et al 2006), aucune anomalie morphologique (ni caryologique) n'est observée. Enfin, bien qu'une perturbation de l'expression placentaire du complexe majeur d'histocompatibilité de classe I (CMH-I) ait été évoquée comme cause de perte fœtale précoce chez certains clones, il semble que cette anomalie ne soit pas généralisable à tous les clones (Hill et al 2002, Chavatte-Palmer et al 2007).

Après le premier trimestre de gestation, des pertes fœtales tardives et des mortalités périnatales ont été mises en évidence. Elles concernent environ 20 à $30 \%$ des gestations initiées alors que dans les conditions naturelles ou après fécondation in vitro, ces pertes sont très rares (moins de 5\%). Il a été montré au laboratoire qu'elles sont souvent associées à un développement excessif du placenta et à la présence d'un hydrallantois (Constant et al 2006). Chez la souris également, plusieurs travaux ont montré que le placenta est fréquemment deux fois plus développé que la normale au cours du développement de fœtus clonés (Tanaka et al 2001, Jouneau et al 2006).

Aux stades plus tardifs, les fœtus clonés issus d'avortement ont souvent un poids plus élevé que la normale et une croissance asynchrone de plusieurs organes avec un développement excessif du cœur et du foie ; mais un développement réduit des poumons et de la rate. Les veaux clonés qui meurent après la mise bas sont le plus souvent victimes d'une détresse respiratoire aiguë ou de malformations cardiaques fréquentes et semblent plus sensibles que la normale aux risques infectieux (Renard et al 1999, Hill et al 1999, Hill et Chavatte-Palmer 2002).
Les veaux viables issus de transfert de noyau somatique manifestent souvent, mais transitoirement, des épisodes d'hyperthermie et des dérégulations hormonales et métaboliques avec, par exemple, des concentrations plasmatiques élevées en leptine et réduites en tétra-iodothyronine (T4) et une augmentation de la concentration plasmatique en fructose ; ils peuvent aussi présenter une relative anémie au cours des premières semaines de vie postnatale en comparaison avec des animaux témoins issus de reproduction sexuée (Batchelder et al $2007 \mathrm{a}$ et b)

Un retard de puberté d'environ deux mois est observé avec les femelles issues de clonage (Enright et al 2002, Heyman et al 2007c) ce qui nous fait considérer que les clones bovins n'acquièrent un statut physiologique normal qu'à partir de 8 à 10 mois. Audelà, leur comportement sexuel est normal et les animaux sont fertiles tant après insémination artificielle qu'après fécondation in vitro. Nous avons aussi engagé une étude de leur comportement et de leurs fonctions cognitives. Nos premiers résultats démontrent un état physiologique et de bien-être comparable à celui d'animaux témoins contemporains (Coulon et al 2007). Chez la souris, un retard de 1 à 2 jours dans l'apparition de signes comportementaux de maturité après la naissance a été rapporté sur quelques critères parmi 10 couramment utilisés. Cependant les tests d'apprentissage spatial, de mémoire, ou d'activités motrices sont apparemment similaires avec les animaux témoins (Tamashiro et al 2003).

Ainsi, rapidement au cours des premiers jours de la vie postnatale, puis progressivement jusqu'à la réalisation des principales fonctions de l'organisme, les animaux clonés acquièrent un état physiologique apparemment normal. C'est ce qui nous a conduit à étudier de plus près cette période de maturation d'un jeune animal issu de clonage, dont la vie semblait compromise mais qui parvient à retrouver un équilibre harmonieux au cours de son développement postnatal. Un faisceau de données provenant d'études sur l'expression de gènes, la méthylation de l'ADN et le remodelage de la chromatine, l'empreinte génomique et l'inactivation du chromosome $\mathrm{X}$ a guidé notre démarche. En effet, ces données tendent à montrer que la reprogrammation nucléaire par transfert de noyau somatique semble être plus efficace dans les cellules de la masse cellulaire interne de l'embryon que dans celles du lignage extra-embryonnaires (Yang et al 2007a). Elles conduisent à considérer que les défauts de reprogrammation affectent surtout les cellules qui vont participer à la formation du placenta : les anomalies placentaires seraient la cause majeure des faibles taux de succès en clonage reproductif, toutes espèces confondues. De plus, les anomalies d'expression de gènes soumis à l'empreinte parentale, présentes dans les fœtus clonés qui n'arrivent pas à terme, ne se retrouvent pas chez les animaux qui se développent normalement après la naissance (Yang et al 2005).

\section{5 / Un programme de recher- ches pluridisciplinaires INRA pour caractériser les animaux clonés et leurs produits}

Les données sur la santé des animaux adultes clonés sont encore limitées étant donné le faible nombre d'animaux présents et le coût des recherches. Les premières études zootechniques publiées présentent souvent le défaut de ne pas comporter de témoins contemporains de même race, même potentiel génétique et élevés dans les mêmes conditions. A l'INRA, un programme pluridisciplinaire de trois ans vient de s'achever qui a intégré des études sur la santé des animaux, (clinique, réponse immunitaire des clones...), leurs performances zootechniques, la composition et la valeur nutritionnelle des produits (lait et viande) ainsi que l'étude des risques de modifications «silencieuses» du génome associées au processus de reprogrammation du noyau après son transfert dans le cytoplasme de l'ovocyte. Une grande partie de nos résultats vient d'être publiée. Nous montrons qu'au-delà de 6 mois d'âge, des clones d'apparence physiologique normale et donc cliniquement sains, ont des productions (lait, viande) non différentes, en termes de composition en substance et de valeur nutritionnelle, de celles des produits dérivés d'animaux reproduits par fécondation (Heyman et al 2007b et c). Mais nous montrons aussi que les perturbations physiologiques qui affectent les animaux clonés au cours de premières semaines de leur vie posnatale peuvent porter atteinte à leur bien-être et doivent en tant que telles être limitées. Ceci pourrait être possible en décelant leur apparition très précocement au cours de la période de vie fœtale. Nous proposons plusieurs pistes et soulignons aussi la nécessité d'analyser les risques génétiques et épigénétiques avant toute décision d'utilisation du 
clonage par l'industrie de la reproduction animale. Ces risques sont actuellement évalués dans le cadre d'un programme européen (le programme SABRE) et les premiers résultats sont en cours d'analyse.

En France, seul l'INRA a produit des animaux clonés à des fins de recherche en s'imposant un moratoire qui rend obligatoire la destruction des clones, produits de clones et descendants des programmes expérimentaux. Mais nos publications sont largement reprises par les agences d'évaluation en charge de la sécurité sanitaire et alimentaire dont les rapports, récemment publiés vont nourrir un débat international qui s'annonce déjà assez vif.

\section{6 / Les positions des agences d'évaluation}

Plusieurs rapports traitant des risques liés à l'utilisation des clones et de leurs descendants (obtenus par reproduction sexuée) dans la chaine alimentaire ont été publiés depuis deux ans. Les trois principaux sont le rapport de la FDA (Food and Drug Administration) pour les USA et ceux de l'EFSA (European Food Safety Agency) et de l'EGE (European Group of Ethics) pour l'Europe.

Ces rapports soulignent tous que la technologie de transfert de noyaux somatiques doit être considérée comme encore récente au vu des données scientifiques disponibles. Les rapports de la FDA et de l'EFSA concordent sur le fait que, au vu de ces données, les clones adultes d'apparence physiologique normale et en bonne santé ne sont pas source de nouveaux risques alimentaires. Cette recommandation est étendue aux descendants des clones, mais avec plus de prudence dans le rapport de l'EFSA qui recommande de confirmer que les modifications épigénétiques susceptibles d'affecter le génome des clones ne seront pas transmises à la génération suivante. Ce rapport souligne l'importance de mieux connaitre les risques génétiques que pourraient représenter des mutations de l'ADN et la présence d'ADN mitochondrial de deux origines différentes induites par le clonage (le cytoplasme de l'ovocyte et le noyau transplanté). Le rapport de la FDA se cantonne à examiner les risques alimentaires. Ceux de l'EFSA et de l'EGE sont préoccupés par les atteintes à la santé et au bien-être des animaux que peut induire le clonage. Mais alors que le rapport de l'EGE considère que ces atteintes au bien-être condamnent cette technique à une utilisation très encadrée en recherche, le rapport de l'EFSA propose des recommandations visant à accompagner une introduction progressive de la technique dans l'économie des productions animales : étude des risques du clonage sur la longévité des animaux ; organisation d'une surveillance et d'un enregistrement de l'état de santé des clones et de leurs descendants au regard de maladies infectieuses en émergence; suivi de l'évolution de l'état de bien-être des animaux clonés dans des conditions normales d'élevage (la plupart des données ont été établies dans des stations expérimentales) ; prévention de l'apparition de développement anormaux le plus tôt possible au cours de la gestation.

Les débats sur l'utilisation ou non des produits des animaux clonés dans les productions animales ne font que commencer, mais le décor est maintenant installé. Ces débats vont concerner essentiellement les bovins et les porcins. Compte tenu du coût élevé de la technique (il faut aujourd'hui environ 10000 à $15000 €$ pour produire un clone bovin) ce sont en priorité des descendants (F1) de taureaux clonés que plusieurs acteurs économiques importants de l'élevage nord et sud américains souhaitent pouvoir produire. Plusieurs dizaines de milliers de doses de semence congelées obtenues à partir de clones de taureaux de haute valeur génétique attendent une autorisation. Dans le même temps, la perception des consommateurs vis-à-vis de l'utilisation des clones dans la chaine alimentaire reste majoritairement négative. L'intérêt de recourir à ces animaux n'est pas clairement identifié et les conditions de vie difficiles auxquelles une minorité des clones doivent faire face dans leur jeune âge sont considérées comme un obstacle.

Jusqu'alors et à la différence de la situation qui a prévalu lors de la genèse des débats sur l'utilisation des plantes génétiquement modifiées (OGM) en agriculture, le débat sur l'utilisation ou non des clones en élevage a pu s'installer alors qu'aucun animal cloné (à partir de noyaux somatiques) ou descendants d'animal cloné n'étaient encore entré dans la chaine alimentaire. Le débat y a gagné en pondération et un véritable dialogue a commencé à s'instaurer en Europe comme en témoignent les travaux du groupe «Cloning in Public» (Gamborg et al 2007), ainsi que la réunion organisée tout récemment entre l'EFSA et une trentaine d'organisations de consommateurs, d'acteurs du monde de l'élevage et d'associations de défense des animaux d'élevage. La décision de la FDA d'autoriser, même progressivement le clonage, les réticences de l'EFSA et l'opposition de l'EGE vont durcir le débat. $\mathrm{Au}$ vu de l'expérience acquise par l'INRA dans le dialogue avec la société, il est peut-être encore temps de participer au niveau international à la construction de nouvelles formes d'échange multipartite entre la recherche et la société. Mais il faut sûrement faire vite pour que les attentes du public envers la recherche ne soient pas ici aussi déçues.

\section{3 / Perspectives}

Au-delà de son intérêt comme outil de recherche, le transfert de noyau peut contribuer à la propagation d'animaux de haut mérite génétique. Son intérêt potentiel dans les schémas d'élevage a déjà été démontré dans le cas du bovin (Colleau et al 1998, Bousquet et Blondin 2004). De plus, les techniques de clonage somatique pourraient être intégrées dans les projets de conservation de certaines espèces en voie d'extinction (Holt et al 2004).

L'association du clonage et de la transgénèse permet également d'envisager nombre d'applications pour l'amélioration des produits animaux parmi lesquelles on peut envisager l'amélioration de la composition des carcasses, des productions de lait ou de laine. Mais, ces produits d'animaux génétiquement modifiés seraient socialement et économiquement peu acceptables dans l'état actuel de la technique. A l'inverse, des animaux de ferme génétiquement modifiés pour l'amélioration de leur résistance aux maladies ou la réduction de leur impact sur l'environnement pourraient être mieux acceptés (Prather et al 2003, Niemann et Kues 2007).

\section{1 / Des exemples concrets d'applications potentielles pour l'élevage}

a) Pour la sélection : le clonage d'un reproducteur d'élite

En cas d'accident d'un taureau producteur de semence au sein d'un centre d'insémination artificielle, le clonage peut être perçu comme une assurance de pouvoir retrouver tout le potentiel génétique investi dans le programme de sélection. A titre de démonstration, un 
essai de clonage du taureau charolais Helsinki appartenant à la coopérative OGER a été tenté en octobre 2000. Il s'agissait de montrer qu'à partir d'une simple biopsie de peau on pouvait sauvegarder le génotype d'un taureau de haute valeur génétique victime d'accident et faire naître en moins d'un an par clonage un animal de même génotype.

Le veau mâle, Helsinki 2, clone du taureau Helsinki est né dans l'Unité Expérimentale (UE) INRA de Bressonvilliers en septembre 2001. Cet animal a été élevé et suivi au sein de cette UE. Ses données de santé et de croissance ont été enregistrées, et il a montré un développement tout à fait normal jusqu'à l'age adulte. Dans le cadre d'une convention entre l'INRA et l'Union Nationale des Coopératives agricoles d'Elevage et d'Insémination Animale (UNCEIA), la fonction spermatique et la fertilité de ce mâle cloné ont été évaluées. Cette étude faisait partie du programme de recherche «Qualité des clones» soutenu par l'INRA visant à mieux connaître les caractéristiques physiologiques et génétiques des clones bovins. Elle a permis de montrer que le clone a eu une production de sperme conforme. En raison d'éventuels risques épigénétiques, nous avons voulu vérifier par une approche de fécondation in vitro que le sperme du clone n'induisait pas de déviation du sex-ratio des embryons par rapport à celui obtenu avec le sperme de l'animal donneur original. Plus de
600 ovocytes de vaches ont été fécondés in vitro par le sperme du donneur ou de son clone et l'aptitude au développement embryonnaire a été la même dans les deux cas, avec une proportion de mâles qui n'était pas différente selon l'origine du sperme (Heyman et al 2007a).

\section{b) Pour la sauvegarde de races en voie d'extinction}

Dans le cas des races domestiques en voie d'extinction, le clonage somatique peut être un outil supplémentaire pour restaurer les derniers exemplaires existant qu'il faudra ensuite multiplier par reproduction sexuée. En France, nous avons pu prélever post mortem une biopsie de peau sur l'une des dernières vaches de «Bazougers», la femelle Aurore, morte en 2001 à l'âge de 17 ans. La vache de Bazougers a surtout une valeur patrimoniale car elle représentait la vache des métayers en Mayenne au 19ème siècle avec près de 2000 animaux à l'époque. Nous avons cloné cet animal à titre expérimental et la vache clonée Aurore B maintenant âgée de 6 ans a déjà produit 3 veaux par insémination artificielle avec de la semence congelée de la même race (figure 2). Son descendant mâle, Augure, a produit des doses de semence congelée avant d'être euthanasié conformément au moratoire INRA. Ces doses ont été déposées à la Cryobanque Nationale en vue d'une utilisation possible ultérieurement en cas de levée du moratoire.

\section{c) Le clonage associé à la transge-} nèse

Le transfert de noyaux dans le cytoplasme d'un ovocyte receveur, associé aux techniques de modifications génétiques ciblées du noyau de la cellule donneuse, a contribué à ouvrir la voie à des transformations mieux contrôlées que celles qui résultent de la seule intégration au hasard d'une séquence d'ADN étranger. De plus, le clonage à partir de cellules modifiées permet de générer des animaux transgéniques modèles avec une bien meilleure efficacité que les méthodes classiques de microinjection (Renard et al 2000). La difficulté de la méthode réside dans le faible taux d'évènements de recombinaison homologue dans les lignées de cellules somatiques en culture primaire, et dans la durée de vie limitée de ces cellules en culture, qui empêche la sélection des cellules transformées. La possibilité d'invalider des gènes chez des clones issus de cellules modifiées a cependant été démontrée chez le mouton, le porc et le bovin (Robl et al 2007). Chez cette dernière espèce, la technique a été optimisée de façon spectaculaire pour conduire à l'obtention d'animaux homozygotes dans lesquels les deux allèles des gènes de l'immunoglobuline-mu (IGHM) et de la protéine du prion (PRNP) ont été invalidés de façon séquentielle (Kuroiwa et al 2004).

L'amélioration de ce type de technique permettra également de produire des animaux modèles porteurs de

Figure 2. Aurore, vache clonée «Bleue de Bazougers», et son veau, descendant obtenu par insémination.

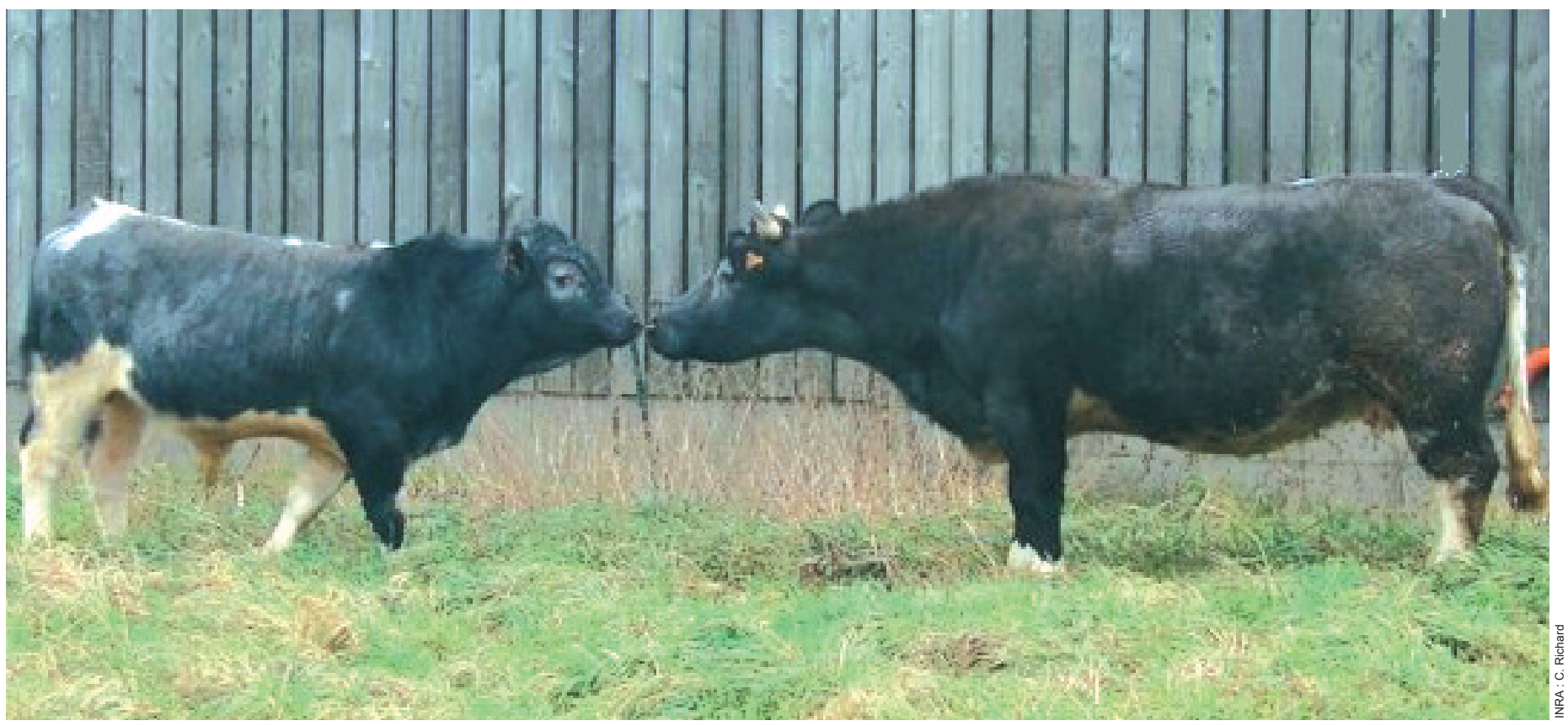


modifications intéressantes pour l'étude de pathologies humaines ou l'analyse fonctionnelle de gènes d'intérêt dans le domaine agronomique. Ainsi, la mutation PIS (Polled Intersex Syndrome) chez la chèvre, qui est associée au développement intéressant d'animaux sans corne, mais aussi à une inversion sexuelle des gonades XX, fait-elle l'objet d'études à l'INRA pour comprendre le phénomène de régulation complexe qui conduit à ce phénotype (Boulanger et al 2008). Ces études de génomique fonctionnelle passent par le recours à l'invalidation de gènes par recombinaison homologue dans des cellules somatiques qui sont utilisées ensuite pour produire des clones porteurs de la modification souhaitée. En l'absence de cellules ES chez les espèces domestiques, le recours au clonage reste le seul moyen pour ce type d'investigation.

\section{2 / De nouvelles pistes pour la recherche}

\section{a) La «reprogrammation» nucléaire}

Le noyau des cellules embryonnaires subit au cours des premiers stades du développement de profonds remaniements structuraux qui conduisent à la mise en place d'une régulation spécifique du génome dans ces cellules en fonction de leur avancement dans la différenciation. L'expression génique des embryons clonés est activement étudiée avec les techniques de haut débit récemment disponibles qui permettent d'avoir des informations sur les profils d'expression, y compris dans des embryons individuels. Les résultats suggèrent que le clonage par transfert de noyau somatique permet une reprogrammation générale importante du noyau somatique (Smith et al 2005), mais que des altérations sont détectées dans la réorganisation épigénétique globale des embryons (Kohda et al 2005 ) et des clones nouveau-nés ou des tissus extra-embryonnaires (Kremenskoy et al 2006). La persistance de dérégulation de l'expression des gènes avant et après l'implantation chez les embryons clonés pourrait être le résultat de la mémoire épigénétique du noyau des cellules donneuses qui n'est pas parfaitement effacée par l'ovocyte (Ng et Gurdon 2005). De plus, certains gènes majeurs essentiels pour le développement des embryons clonés ne sont pas réactivés au cours des phases précoces et des premières étapes de l'ontogénèse (Jouneau et al 2006). L'ensemble des données disponibles dans la littérature permet donc de cibler les mécanismes moléculaires qui sont altérés au cours du clonage somatique et potentiellement en relation avec les anomalies de développement constatées. Elles sont maintenant mises à profit pour tenter d'améliorer l'efficacité de la reprogrammation des noyaux somatiques. Par exemple, un traitement de modification de la structure de la chromatine des noyaux des cellules donneuses par un inhibiteur des histones déacétylases comme la Trichostatin A (TSA) préalablement au transfert nucléaire peut améliorer sensiblement les performances du clonage somatique chez la souris (Wakayama 2007). De tels traitements sont actuellement mis à l'épreuve chez les espèces domestiques, ils pourront être combinés à des approches permettant une analyse moléculaire de la structuration du génome et des modifications épigénétiques qui sont liées au développement embryonnaire (Martin et al 2006).

La variabilité des taux de succès obtenus en clonage animal ne peut être attribuée aux seuls paramètres de génotype de l'animal d'origine ou de l'état de différenciation de la cellule donneuse de noyau (Green et al 2007). Le rôle majeur du cytoplasme ovocytaire démontre l'importance de l'environnement du génome sur les premiers événements du développement et de la différenciation. Des approches permettant un meilleur contrôle de l'environnement lors de ces étapes clés, que ce soit le cytoplasme ovocytaire ou le milieu dans lequel les embryons son cultivés, pourraient permettre de diminuer les variations qui affectent la régulation des gènes au cours de ces processus (Ozil et al 2006).

b) Le transfert de noyaux : un outil pour disséquer l'effet des mécanismes épigénétiques sur le phénotype des animaux

Les phénotypes anormaux associés aux clones ne sont pas transmis à la descendance lors de la reproduction sexuée. La preuve la plus convaincante est sans doute l'absence de transmission de tout caractère délétère génétique ou épigénétique lors du croisement de souris clone mâles et femelles obtenues à partir d'une même lignée cellulaire (cellules ES XY et XO, Shimozawa et al 2002). Les descendants sont phénotypiquement normaux et la gestation se déroule sans l'apparition des anomalies de taille du fotus ou du placenta qui étaient caractéristiques des parents clonés. Ces observations suggèrent bien que les anomalies de développement liées au clonage sont d'origine épigénétique, et que les erreurs éventuelles des clones sont effacées ou corrigées durant la gamétogenèse. De même, les descendants de génisses clonées ont un poids de naissance normal et ne présentent aucune des anomalies décrites pour les clones eux-mêmes (Lanza et al 2001, Heyman et al 2004, Wells et al 2004). Des descendants de clones mâles et femelles ont été obtenus chez plusieurs espèces, à la fois en croisement naturel et en insémination artificielle ou en croisement avec un partenaire non cloné. Fécondation, gestation, mise bas et survie postnatale sont toutes normales, ainsi que la fertilité des animaux descendants de clones (Heyman et al 2007a, Ortegon et al 2007). Il est cependant nécessaire de vérifier au niveau moléculaire si les modifications épigénétiques dans les gamètes, zygotes et embryons dérivés de clones sont effectivement ramenés à un état normal. Il existe en effet des démonstrations de transmission par la lignée germinale de modifications épigénétiques (Roemer et al 1997) ; et des anomalies chromosomiques ont été rapportées chez des bovins clonés apparemment en bonne santé (Hanada et al 2005). Il reste donc à savoir, à un niveau pratique, si les descendants d'un clone ont des performances phénotypiques similaires à l'animal d'origine.

\section{c) Les effets à long terme, program- mation fotale}

Les causes de mortalité chez les clones adultes sont encore peu documentées. En dépit de la variabilité des poids de naissance chez les clones, la croissance des animaux clonés apparaît normale, en accord avec les prévisions génétiques et, contrairement à la souris, aucun cas d'obésité n'a encore été rapporté chez les clones d'animaux domestiques à 1'âge adulte (Pace et al 2002, Heyman et al 2004, Wells e et al 2004). De plus, les concentrations plasmatiques en hormone de croissance $(\mathrm{GH})$ et la réponse à la stimulation par l'hormone hypothalamique GHRH sont normales (Govoni et al 2002). Une étude clinique incluant l'étude des paramètres biochimiques classiques et un typage lymphocytaire succinct a conclu que les animaux clonés étaient en bonne santé et normaux (Lanza et al 2001). Dans une étude comparative en cours à l'INRA, les résultats préliminaires ne montrent pas de différences significatives à l'âge adulte sur les animaux vivants. Cependant, ces résultats n'expliquent pas la mortalité un peu plus importante chez les clones et ils n'excluent pas la possibilité d'une sensibilité 
augmentée vis-à-vis de stress extérieurs.

Des études épidémiologiques conduites chez l'homme ont démontré une incidence accrue de physiopathologies chez l'adulte en relation avec un développement fotal perturbé des mêmes individus (Barker 2004). Chez les animaux, il a été confirmé que la sousnutrition fotale conduit à une adaptation à cet environnement altéré par modification du métabolisme, ces modifications demeurent après la naissance (Mc Millen et Robinson 2005). Ces études expérimentales indiquent que les relations entre nutrition maternelle, croissance fœtale et pathologies adultes peuvent avoir une origine très précoce, même à des périodes restreintes post-fécondation. Les approches issues de la génomique permettent de coupler l'analyse systématique d'organes en développement (placenta dès le début du développement embryonnaire par exemple) avec des approches moléculaires à haut débit de façon à identifier les gènes et réseaux de gènes qui peuvent être impliqués dans la santé des animaux à différents stades de leur développement fœtal et postnatal (Everts et al 2007). Dès lors que des défauts du développement placentaire sont une des causes principales d'anomalie et de mortalité chez les clones (Chavatte-Palmer et al 2002), l'analyse de la mise en place de ce tissu en fonction de différentes origine des embryons (production in vitro, clonage ou fécondation) devrait être approfondie.

\section{d) Etude des risques associés au clonage}

Si on a vu que la mortalité était importante chez les animaux jeunes issus de clonage, il n'en reste pas moins que bon nombre d'animaux d'apparence physiologique normale se développent en adultes sans problème particulier. Cependant, les différences épigéné- tiques entre individus d'un même clone somatique font que leurs performances sont plus variables que celles observées au sein d'un couple de jumeaux monozygotes. De plus, dans la perspective d'utilisation d'animaux clonés comme reproducteurs, il importe de s'assurer de l'intégrité du génome entre le donneur et son clone. En effet, des mutations ont pu apparaître dans les cellules utilisées comme donneuses de noyau, soit avant leur prélèvement sur l'animal adulte, soit au cours de la période de culture in vitro qui précède le clonage. Pour cela, des approches permettant la détection de polymorphisme de séquence entre deux génomes ou des différences de méthylation ont été mises en place au laboratoire (De Montera et al 2004). L'objectif est d'évaluer jusqu'à quel point les clones sont identiques génétiquement.

\section{Conclusions}

Les progrès du clonage animal ont conduit à considérer l'implication des animaux domestiques bien au-delà de leur usage traditionnel en agriculture ou dans les domaines de la recherche biomédicale. Le transfert de noyaux a non seulement confirmé l'importance des événements épigénétiques dans la plasticité fonctionnelle du génome, mais également révélé le potentiel de l'embryon de mammifère à s'adapter aux perturbations de l'environnement tout au long du processus de développement. Les clones et le transfert d'embryon chez les animaux de ferme auront un rôle scientifique clé dans l'ère de la post-génomique dont un des challenges est l'analyse et la compréhension de l'ontogenèse des systèmes biologiques complexes. L'impact principal du clonage en élevage sera finalement peut-être plus lié à l'aptitude de cet outil à permettre d'étudier, voire de modéliser, les liens entre des événements précoces de la régulation génique avec le phénotype et les aptitudes des animaux adultes qu'à son intérêt potentiel en reproduction pure et simple.

Dans le même temps cependant, les expertises scientifiques sur l'évaluation de la sécurité alimentaire et génétique des clones et leurs produits devront être complétées par des études sur la descendance de ces animaux, même si les études conduites en Europe, au Japon ou aux USA n'ont pas identifié de risque significatif pour la consommation de produits alimentaires dérivés de bovins, porcins ou caprins clonés. Ces expertises devraient être accompagnées d'approches interdisciplinaires avec les sciences sociales, ceci afin d'aboutir à une gestion de l'utilisation de cette biotechnologie qui soit en accord avec les débats de société soulevés par la réalité du clonage somatique au cours des dix dernières années. C'est sans doute l'assurance d'une confiance durable et nécessaire entre les acteurs de la recherche, les filières d'élevage et les consommateurs.

\section{Remerciements}

Les auteurs tiennent particulièrement à remercier l'ensemble des animaliers de l'Unité Commune d'Expérimentation Animale (UCEA) pour leur implication dans la préparation des animaux, le suivi des gestations et la surveillance particulièrement rapprochée des animaux clonés après leur naissance. Les travaux présentés ont pu être réalisés grâce aux personnes impliquées dans l'atelier MIV-FIV de Jouy-en-Josas : N. Peynot, Y. Lavergne, C. Audouard ; et dans la culture de cellules donneuses de noyau : E. Laloy, S. Péron, P. Bodinier. Enfin bien sûr, le clonage à l'INRA n'aurait pu être réussi sans le travail acharné des personnes en charge de la micromanipulation : N. Daniel, D. Le Bourhis (UNCEIA), V. Brochard et P. Chesné.

\section{Références}

Adenot P.G.., Szöllözi M.S., Chesné P., Chastant S., Renard J.P., 1997. In vivo aging of oocytes influences the behavior of nuclei transferred to enucleated rabbit oocytes. Mol. Reprod. Dev., 46, 325-336.

Baguisi A., Behboodi E., Melican D.T., Pollock J.S., Destrempes M.M., Cammuso C., Williams J.L., Nims S.D., Porter C.A., Midura P., Palacios M.J., Ayres S.L., Denniston RS., Hayes M.L., Ziomek C.A., Meade H.M., Godke R.A., Gavin W.G., Overström E.W., Echelard Y., 1999. Production of goats by somatic cell nuclear transfer. Nature Biotech., 17, 456-461.
Barker D.J.P., 2004. Developmental origins of adult health and disease. J. Epidemiol. Community Health, 58, 114-115.

Batchelder C.A., Bertolini M., Mason J.B., Moyer A.L., Hoffert K.A., Petkov S.G., Famula T.R., Angelos J., George L.W., Anderson G.B., 2007a. Perinatal physiology in cloned and normal calves: hematologic and biochemical profiles. Cloning Stem Cells, 9, 83-96.

Batchelder C.A., Bertolini M., Mason J.B., Moyer A.L., Hoffert K.A., Petkov S.G., Famula T.R., Angelos J., George L.W., Anderson G.B., 2007b. Perinatal physiology in cloned and nor- mal calves: physical and clinical characteristics. Cloning Stem Cells, 9, 63-82.

Beaujean N., Martin C., Debey P., Renard J.P., 2005. Reprogramming and epigenesis. Med. Sci., 21, 412-421.

Boulanger L., Kocer A., Daniel N., Pannetier M., Chesné P., Heyman Y., Reanult L., MandonPépin B., Chavatte-Palmer P., Vignon X., Cotinot C., Renard J.P., Pailhoux E., 2008. Attempt to rescue sex-reversal by transgenic expression of the PISRT1 gene in XX PIS-/goats. Sex. Dev., accepté 
Bousquet D., Blondin P., 2004. Potential uses of cloning in breeding schemes: dairy cattle. Cloning Stem Cells, 6, 190-197.

Buttler D., 1998. French clone provides support for Dolly. Nature, 392, 113.

Chavatte-Palmer P., Heyman Y., Richard C., Monget P., Le Bourhis D., Kann G., Chilliard Y., Vignon X., Renard J.P., 2002. Clinical, hormonal, and hematologic characteristics of bovine calves derived from nuclei from somatic cells. Biol. Reprod., 66, 1596-1603.

Chavatte-Palmer P., Rémy D., Cordonnier N., Richard C., Issenman H., Laigre P., Heyman Y., Mialot J.P., 2004. Health status of cloned cattle at different ages. Cloning Stem Cells, 6, 94-100.

Chavatte-Palmer P., De Sousa N., Laigre P., Camous S., Ponter A.A., Beckers J.F., Heyman Y., 2006. Ultrasound fetal measurements and pregnancy associated glycoprotein secretion in early pregnancy in cattle recipients carrying somatic clones. Theriogenology, 66, 829-840.

Chavatte-Palmer P., Guillomot M., Roiz J., Heyman Y., Laigre P., Servely J.L., Hue I., Constant F., Ellis S., 2007. Placental expression of major histocompatibility complex class 1 in bovine somatic clones. Cloning Stem Cells, 9, 346-356.

Chesné P., Heyman Y., Peynot N., Renard J.P., 1993. Nuclear transfer in cattle: birth of cloned cattle and estimation of blastomere totipotency in morulae used as source of nuclei. C.R. Acad. Sci., 316, 487-491.

Chesné P., Adenot P. G., Viglietta C., Baratte M., Boulanger L., Renard J.P., 2002. Cloned rabbits produced by nuclear transfer from adult somatic cells. Nat. Biotech.., 20, 366-369.

Cibelli J.B., Stice S.L., Golueke P.J., Kane J.J., Jerry J., Blackwell C., Ponce de Leon F.A., Robl J.M., 1998. Cloned transgenic calves produced from nonquiescent fetal fibroblasts. Science, 280, 1256-1258.

Colleau J.J., Heyman Y., Renard J.P., 1998. Les biotechnologies de la reproduction chez les bovins et leurs applications réelles ou potentielles en sélection. INRA Prod. Anim., 11, 41-56.

Constant F., Guillomot M., Heyman Y., Vignon X., Laigre P., Servely J.L., Renard J.P., Chavatte-Palmer P., 2006. Large offspring syndrome or large placenta syndrome? Morphometric analysis of late gestation bovine placentomes from somatic nuclear transfer pregnancies complicated by hydroallantois. Biol. Reprod., 75, 122-130.

Coulon M., Baudoin C., Depaulis-Carré M., Heyman Y., Renard J.P., Richard C., DePutte B., 2007. Dairy cattle exploratory and social behaviors: is there an effect of cloning? Theriogenology, 68, 1097-1103.

Degrelle S.A., Campion E., Cabau C., Piumi F., Reinaud P., Richard C., Renard J.P., Hue I., 2005. Molecular evidence for a critical period in mural trophoblast development in bovine blastocysts. Dev. Biol., 288, 448-460.

De Montera B., Boulanger L., Taourit S., Renard J.P., Eggen A., 2004. Genetic identity of clones and methods to explore DNA. Cloning Stem Cells, 6, 133-139.

EFSA, 2008. Draft opinion for public consultation http://www.efsa.europa.eu/EFSADocumentSet/sc_opinion_clon_public consultation. pdf

Enright B.P., Taneja M., Schreiber D., Riesen J., Tian X.C., Fortune J.E., Yang X., 2002.
Reproductive characteristics of cloned heifers derived from adult somatic cells. Biol. Reprod., 66, 291-296.

Everts R.E., Chavatte-Palmer P., Razzak A., Hue I., Green C.A., Oliveira R., Vignon X., Rodriguez-Zas S.L., Tian X.C., Yang X., Renard J.P., Lewin H.A., 2008. Aberrant gene expression patterns in placentomes are associated with phenotypically normal and abnormal cattle cloned by somatic cell nuclear transfer. Physiol. Genomics, 33, 65-77.

Gall L., Lebourhis D, Ruffini S, Boulesteix C., Vignon X., 2008. Unexpected nuclear localization of $\mathrm{Cdc} 25 \mathrm{c}$ in bovine oocytes, early embryos and nuclear-transferred embryos. Reproduction, sous presse.

Galli C., Lagutina I., Crotti G., Colleoni S., Turini P., Ponderato N., Duchi R., Lazzari G., 2003. A cloned horse born to its dam twin. Nature, 424, 635 .

Gamborg C., Jerris M., Gunning J., Hartlev M., Meyer G., Sandoe P., Tveit G., 2007. Regulating farm animal cloning. Recommendations from project «Cloning in Public». http://www.sl.kvl.dk/cloninginpublic/index-filer/RecommendationsreportCIP.pdf

Govoni K.E., Tian X.C., Kazmer G.V., Taneja M., Enright B.P., Rivard A.L., Yang X., Zinn S.A., 2002. Age-related changes of the somatotropic axis in cloned holstein calves. Biol. Reprod., 66, 1293-1298.

Green A.L., Wells D.N., Oback B., 2007. Cattle cloned from increasingly differentiated muscle cells. Biol. Reprod., 77, 395-406.

Hanada H., Takeda K., Tagami T., Nirasawa K., Akagi S., Adachi N., Takahashi S., Izaike Y., wamoto M., Fuchimoto D., Miyashita N., Kubo M., Onishi A., King W.A., 2005. Chromosomal instability in the cattle clones derived by somatic cell nuclear-transfer. Mol. Reprod. Dev., 71, 36-44.

Heyman Y., Chesné P., Renard J.P., 1990. Reprogrammation complète de noyaux embryonnaires congelés, après transfert nucléaire chez le lapin. C.R. Acad. Sci., 311, 321-326.

Heyman Y., Chavatte-Palmer P., Le Bourhis D., Camous S., Vignon X., Renard J.P., 2002. Frequency and occurrence of late gestation losses from cattle cloned embryos. Biol. Reprod., $66,6-13$.

Heyman Y., Richard C., Rodriguez-Martinez H., Lazzari G., Chavatte-Palmer P., Vignon X., Galli C., 2004. Zootechnical performance of cloned cattle and offspring: preliminary results. Cloning Stem Cells, 6, 111-120.

Heyman Y., Chavatte-Palmer P., Vignon X., Richard C., Renard J.P., 2005. Le clonage somatique : un état des lieux chez les bovins et les petits ruminants. INRA Prod. Anim., 18, 339354

Heyman Y., LeGuienne B., Audouard C., Charreaux F., Humblot P., Vignon X., 2007a. Sex-ratio of in vitro produced blastocysts obtained using frozen semen from a cloned bull or its original cell donor. Reprod. Fertil. Dev., 19, 296.

Heyman Y., Chavatte-Palmer P., Berthelot V., Fromentin G., Hocquette J.F., Martignat L., Renard J.P., 2007b. Assessing the quality of products from cloned cattle: an integrative approach. Theriogenology, 67, 134-141.

Heyman Y., Chavatte-Palmer P., Fromentin G., Berthelot V., Jurie C., Bas P., Dubarry M., Mialot J.P., Rémy D., Richard C., Martignat L., Vignon X., Renard J.P., 2007c. Quality and safe- ty of bovine clones and their products. Animal $1,963-972$.

Hill J.R., Roussel A.J., Cibelli J.B., Edwards J.F., Hooper N.L., Miller M.W., Thompson J.A., Looney C.R., Westhusin M.E., Robl J.M., Stice S.L., 1999. Clinical and pathologic features of cloned transgenic calves and fetuses (13 cases studies). Theriogenology, 51, 1451-1465.

Hill J.R., Chavatte-Palmer P., 2002a. Pregnancy and neonatal care of cloned animals. In: Principles of cloning. Cibelli J. (Ed), Academic Press, San Diego, USA, 247-266.

Hill J.R., Schlafer D.H., Fisher P.J., Davies C.J., 2002b. Abnormal expression of trophoblast major histocompatibility complex class I antigens in cloned bovine pregnancies is associated with a pronounced endometrial lymphocytic response. Biol. Reprod., 67, 55-63.

Holt W.V., Pickard A.R., Prather R.S., 2004. Wildlife conservation and reproductive cloning. Reproduction, 127, 317-324.

Jouneau A., Zhou Q., Camus A., Brochard V., Maulny L., Collignon J., Renard J.P., 2006. Developmental abnormalities of NT mouse embryos appear early after implantation. Development, 133, 1597-1607.

Kato Y., Tani N., Sotomaru Y., Kurokawa K., Kato J., Doguchi H., Yasue H., Tsunoda Y. 1998. Eight calves cloned from somatic cells of a single adult. Science, 282, 1975-1976.

Kohda T., Inoue K., Ogonuki N., Miki H., Naruse M., Kaneko-Ishino T., Ogura A., Ishino F., 2005. Variation in gene expression and aberrantly regulated chromosome regions in cloned mice. Biol. Reprod., 73, 1302-1311.

Kremenskoy M., Kremenska Y., Suzuki M., Imai K., Takahashi S., Hashizume K., Yagi S., Shiota K., 2006. DNA methylation profiles of donor nuclei cells and tissues of cloned bovine fetuses. J. Reprod. Dev., 52, 259-266.

Kuroiwa Y., Kasinathan P., Matsushita H., Sathiyaselan J., Sullivan E.J., Kakitani M., Tomizuka K., Ishida I., Robl J.M., 2004. Sequential targeting of the genes encoding immunoglobulin-mu and prion protein in cattle. Nat. Genet., 36, 775-780.

Lanza R.P., Cibelli J.B., Faber D., Sweeney R.W., Henderson B., Nevala W., West M.D., Wettstein P.J., 2001. Cloned cattle can be healthy and normal. Science, 294, 1393-1394.

Le Bourhis D., Chesné P., Nibart M., Marchal J., Humblot P., Renard J.P., Heyman Y., 1998. Nuclear transfer from sexed parent embryos in cattle: efficiency and birth of offspring. J. Reprod. Fertil., 113, 343-348.

Li S., Chen X., Fang Z., Shi J., Sheng H.Z., 2006. Rabbits generated from fibroblasts through nuclear transfer. Reproduction, 131, 1085-1090.

Martin C., Brochard V., Migné C. Zink D., Debey P., Beaujean N., 2006. Architectural reorganization of the nuclei upon transfer into oocytes accompanies genome reprogramming. Mol. Reprod. Dev., 73, 1102-1111.

McMillen C., Robinson J.S., 2005. Developmental origins of the metabolic syndrome: prediction, plasticity, and programming. Physiol. Rev., 85, 571-633.

Meissner A., Jaenisch R., 2006. Mammalian nuclear transfer. Dev. Dynamics, 235, 2460 2469

Meng Q., Polgar Z., Liu J., Dinnyes A., 2008. Effect of trichostatin treatment on the term 
development of somatic cell nuclear transfer rabbit embryos. Reprod. Fert. Dev., 20, 103.

Ng R.K., Gurdon J.B., 2005. Epigenetic memory of active gene transcription is inherited through somatic cell nuclear transfer. Proc. Natl. Acad. Sci. USA, 102, 1957-1962.

Niemann H., Kues W.A., 2007. Transgenic farm animals: an update. Reprod. Fertil. Dev., 19, 762-770

Onishi A., Iwamoto M., Akita T., Mikawa S., Takeda K., Awata T., Hanada H., Perry A.C., 2000. Pig cloning by microinjection of fetal fibroblast nuclei. Science, 289, 1188-1190.

Ortegon H., Betts D., Lin L., Coppola G., Perrault S., Blondin P., King W., 2007. Genomic stability and physiological assessments of live offspring sired by a bull clone, Starbuck II. Theriogenology, 67, 116-126.

Ozil J.P., Heyman Y., Renard J.P., 1982. Production of monozygotic twins by micromanipulation and cervical transfer in the cow. Vet. Rec., 110, 126-127.

Ozil J.P., Banrezes B., Toth S., Pan H., Schultz R.M., 2006. Ca2+ oscillatory pattern in fertilized mouse eggs affects gene expression and development to term. Dev. Biol., 300, 534-544.

Pace M.M., Augenstein M.L., Betthauser J.M., Childs L.A., Eilertsen K.J., Enos J.M., Forsberg E.J., Golueke P.J., Graber D.F., Kemper J.C., Koppang R.W., Lange G., Lesmeister T.L., Mallon K.S., Mell G.D., Misica P.M., PfisterGenskow M., Strelchenko N.S., Voelker G.R., Watt S.R., Bishop M.D., 2002. Ontogeny of cloned cattle to lactation. Biol. Reprod., 67, 334339.

Panarace M., Aguero J.I., Garrote M., Jauregui G., Segovia A., Cane L., Gutierrez J., Marfil M., Rigali F., Pugliese M., 2007. How healthy are clones and their progeny: 5 years of field experience. Theriogenology, 67, 142-151.

Polejaeva I.A., Chen S.H., Vaught T.D., Page R.L., Mullins J., Ball S., Dai Y., Boone J., Walker S., Ayares D.L., Colman A., Campbell K.H.S., 2000. Cloned pigs produced by nuclear transfer from adult somatic cells. Nature, 407, 86-90.

Prather R.S., Hawley R.J., Carter D.B., Lai L., Greenstein J.L., 2003. Transgenic swine for biomedicine and agriculture. Theriogenology, 59, 115-123.
Renard J.P., 1998. Chromatin remodeling and nuclear reprogramming at the onset of embryonic development in mammals. Reprod. Fertil. Dev., 10, 573-580.

Renard J.P. Chastant S., Chesné P., Richard C., Marchal J., Cordonnier N., Chavatte P. Vignon X., 1999. Lymphoid hypoplasia and somatic cloning. The Lancet, 353, 1489-1491.

Renard J.P., Boulanger L., Vignon X., 2000. Plasticité du génome et totipotence nucléaire : application à la transgénèse par clonage chez les mammifères d'élevage. C.R. Acad. Agric. Fr., 86, 83-97.

Renard J.P., Zhou Q, Le Bourhis D., ChavattePalmer P., Hue I., Heyman Y., Vignon X., 2002. Nuclear transfer technologies: between successes and doubts. Theriogenology, 57, 203-222.

Renard J.P., Maruotti J., Jouneau A., Vignon X., 2007. Nuclear reprogramming and pluripotency of embryonic cells: application to the isolation of embryonic stem cells in farm animals. Theriogenology, 68 (Suppl 1), S196-S205.

Robl J.M., Wang Z., Kasinathan P., Kuroiwa Y., 2007. Transgenic animal production and animal biotechnology. Theriogenology, 67, $127-$ 133.

Roemer I., Reik W., Dean W., Klose J., 1997. Epigenetic inheritance in the mouse. Curr. Biol. 7, 277-280.

Shimozawa N., Ono Y., Kimoto S., Hioki K., Araki Y., Shinkai Y., Kono T., Ito M., 2002. Abnormalities in cloned mice are not transmitted to the progeny. Genesis, 34, 203-207.

Smith S.L., Everts R.E., Tian X.C., Du F., Sung L.Y., Rodriguez-Zas S.L., Jeong B.S., Renard J.P., Lewin H.A., Yang X., 2005. Global gene expression profiles reveal significant nuclear reprogramming by the blastocyst stage after cloning. Proc. Natl. Acad. Sci. USA, 102, 17582-17597.

Tamashiro K.L., Wakayama T., Yamazaki Y., Akutsu H., Woods S.C., Kondo S., Yanagimachi R., Sakai R.R., 2003. Phenotype of cloned mice: development, behavior, and physiology. Exp. Biol. Med., 228, 1193-1200.

Vignon X., Chesné P., Le Bourhis D., Fléchon J.E., Heyman Y., Renard J.P., 1998. Developmental potential of bovine embryos reconstructed from enucleated matured oocytes fused with cultured somatic cells. C.R. Acad. Sci., 321, 735-745.
Vignon X., Zhou Q., Renard J.P., 2002. Chromatin as a regulative architecture of the early developmental functions of mammalian embryos after fertilization or nuclear transfer. Cloning Stem Cells, 4, 363-377.

Wakayama T., 2007. Production of cloned mice and ES cells from adult somatic cells by nuclear transfer: how to improve cloning efficiency? J. Reprod. Dev., 53, 13-26.

Wakayama T., Perry A.C., Zuccotti M., Johnson K.R., Yanagimachi R., 1998. Full-term development of mice from enucleated oocytes injected with cumulus cell nuclei. Nature, 394, 369-374.

Wells D.N., Misica P.M., Tervit H.R., Vivanco W.H., 1998. Adult somatic cell nuclear transfer is used to preserve the last surviving cow of Enderby Island cattle breed. Reprod. Fertil. Dev., 10, 369-378.

Wells D., Forsyth J.T., McMillan V., Oback B., 2004. The health of somatic cell cloned cattle and their offspring Cloning Stem Cells, 6, 101110 .

Wilmut I., Schnieke A.E., McWhir J., Kind A.J., Campbell K.H.S., 1997. Viable offspring derived from fetal and adult mammalian cells. Nature, $385,810-813$.

Willadsen S.M., 1986. Nuclear transplantation in sheep embryos. Nature, 320, 63-65.

Yang L., Chavatte-Palmer P., Kubota C. O'Neill M., Hoagland T., Renard J.P., Taneja M., Yang X.Z., Tian X.C., 2005. Expression of imprinted genes is aberrant in deceased newborn cloned calves and relatively normal in surviving adult clones. Mol. Reprod. Dev., 71, 431-438.

Yang X., Smith S.L., Tian X.C., Lewin H.A., Renard J.P., Wakayama T., 2007. Nuclear reprogramming of cloned embryos and its implications for therapeutic cloning. Nat. Genet., 39, 295-302.

Zhou Q., Jouneau A., Brochard V., Adenot P. Renard J.P., 2001. Developmental potential of mouse embryos reconstructed from metaphase embryonic stem cell nuclei. Biol. Reprod., 65, 412-419.

Zhou Q., Renard J.P., Le Friec G., Brochard V., Beaujean N., Cherifi Y., Fraichard A., Cozzi J., 2003. Generation of fertile cloned rats by regulating oocyte activation. Science, 302, 1179.

\section{Résumé}

La reproduction d'espèces domestiques par clonage remonte à plus de 20 ans. Les premières techniques reposent sur la bissection d'embryons puis sur l'usage de cellules embryonnaires pour générer des animaux clonés par transfert de noyau. Avec l'apparition du clonage somatique, qui permet la préservation et l'obtention de descendants de génotypes de haute valeur, l'intérêt pour cette technologie s'est considérablement accru. Un retour sur ces 20 dernières années montre comment l'INRA s'est impliqué dans la mise au point méthodologique du clonage animal et a acquis une expertise reconnue, non seulement dans la production et l'analyse de clones d'animaux domestiques, mais également dans l'étude du rôle des altérations génétiques et épigénétiques dans le développement embryonnaire, foetal et postnatal chez ces animaux. Le clonage reste en effet peu efficace pour la production d'individus viables en comparaison d'autres techniques de reproduction assistée. Une meilleure compréhension de la reprogrammation épigénétique des noyaux de cellules somatiques et de ses effets sur le déroulement des gestations est nécessaire pour rendre cette technologie éthiquement et économiquement acceptable. $L$ 'acceptation des produits de clones dans l'alimentation dépend maintenant de l'approbation des agences d'évaluation. Celle-ci est basée sur l'acquisition de données scientifiques concernant la sécurité et l'équivalence des produits avec ceux qui sont issus d'animaux reproduits par fécondation. Cette synthèse fait le point sur les principales connaissances fondamentales sur le clonage somatique, depuis la cellule donneuse, jusqu'au descendant cloné, et leurs liens avec la santé, la viabilité, les caractéristiques quantitatives et de reproduction des individus clonés. 


\begin{abstract}
Reproduction biotechnology: cloning of livestock

Reproduction of domestic species by cloning has been conducted for more than 20 years. Early techniques relied first on embryo splitting, then on using embryo cells for nuclear transfer to generate cloned animals. The advent of nuclear transfer now enables the use of somatic adult cells for the direct transfer and preservation of high-value genotypes to offspring. In this article, a summary is presented of how INRA, during the last 20 years, has brought technical improvement and scientific expertise in cloning technology, not only for the production of cloned laboratory and domestic species, but also for the study of how nuclear transfer has an influence on genetic and epigenetic regulation of embryonic, fetal and postnatal development in these animals. Somatic cell nuclear transfer is still a poorly efficient technique to generate live offspring. The acceptance of clones and products of clones in the food chain depends on societal discussions and evaluations from food agencies, which are based on scientific data on safety and equivalence of these products with those issued from fertilised animals. This synthesis shows how important it is to investigate every step of somatic cell nuclear transfer more intensively, starting from the donor cell and continuing until the cloned offspring are born and further.
\end{abstract}

VIGNON X., HEYMAN Y., CHAVATTE-PALMER P., RENARD J.-P., 2008. Biotechnologies de la reproduction : le clonage des animaux d'élevage. INRA Prod. Anim., 21, 33-44. 